\title{
Some inequalities for the $s$-Godunova-Levin type functions
}

\author{
M. Emin Özdemir
}

Received: 24 September 2014/ Accepted: 23 February 2015/Published online: 17 March 2015

(C) The Author(s) 2015. This article is published with open access at Springerlink.com

\begin{abstract}
In this paper, first, we obtained two new sGodunova-Levin type inequalities about "the mean value Theorem for integrals". Second, some inequalities were proved for mappings $q$ th powers of first derivatives belonging to class $Q_{s}(I)$ using the Čebyšev's inequality, $\mathrm{H}$ ölder inequality, Power mean inequality, and some other classical inequalities. Finally, some error estimates for the Trapezoidal formula are also given. The results obtained are consistent with literature.
\end{abstract}

Keywords Hadamard's inequality - Differentiable mappings $\cdot s$-Godunova-Levin type functions $\cdot$ Fractional integral · Power mean inequality

\section{Introduction}

One of the most famous inequalities for convex functions is Hadamard's inequality. This double inequality is stated as follows (see for example [1,2]): Let $f: I \subset \mathbb{R} \rightarrow \mathbb{R}$ be a convex function on the interval $I$ of real numbers and $a, b \in I$ with $a<b$. Then

$f\left(\frac{a+b}{2}\right) \leq \frac{1}{b-a} \int_{a}^{b} f(x) \mathrm{d} x \leq \frac{f(a)+f(b)}{2}$.

For several recent results concerning the inequality (1), we refer the interested reader to [1-5].

M. E. Özdemir ( $₫)$

Department of Mathematics, K.K. Education Faculty, Atatürk

University, Kampus, 25240 Erzurum, Turkey

e-mail: emos@atauni.edu.tr
Definition 1 [6] We say that $f: I \rightarrow \mathbb{R}$ is a GodunovaLevin function or that $\mathrm{f}$ belongs to class $\mathrm{Q}(\mathrm{I})$ if $\mathrm{f}$ is nonnegative and for all $x, y \in I$ and $t \in(0,1)$ we have

$f(t x+(1-t) y) \leq \frac{1}{t} f(x)+\frac{1}{1-t} f(y)$.

Some further properties of this class of functions can be found in [7-12]. Among others, it has been noted that nonnegative monotone and non-negative convex functions belong to this class of functions. The above concept can be extended for functions $f: C \subseteq X \rightarrow[0, \infty)$ where $\mathrm{C}$ is a convex subset of the real or complex linear space $\mathrm{X}$ and the inequality (2) is satisfied for any vectors $x, y \in C$ and $t \in(0,1)$. If the function $f: C \subseteq X \rightarrow \mathbb{R}$ is non-negative and convex, then it is of Godunova-Levin type.

Definition 2 Let $s$ be a real number, $s \in(0,1]$. A function $f:[0, \infty) \rightarrow[0, \infty)$ is said to be s-convex (in the second sense)

$f(t x+(1-t) y) \leq t^{s} f(x)+(1-t)^{s} f(y)$

for all $x, y \in[0, \infty)$ and $t \in[0,1]$.

For some properties of this class of functions see [13-17].

This concept can be extended for functions defined on convex subsets of linear spaces in the same way as above replacing the interval $I$ be the corresponding convex subset $C$ of the linear space $X$ :

Definition 3 [18] We say that the function $f: C \subset X \rightarrow$ $[0, \infty)$ is of $s$-Godunova-Levin type, with $s \in[0,1]$, if

$f(t x+(1-t) y) \leq \frac{1}{t^{s}} f(x)+\frac{1}{(1-t)^{s}} f(y)$

for all $t \in(0,1)$ and $x, y \in C$. 
We denote by $Q_{s}(C)$ the class of $s$-Godunova-Levin functions defined on $C$.

We observe that for $s=0$, we obtain the class of $p$ functions while for $s=1$ we obtain the class of GodunovaLevin. Thus,

$P(C)=Q_{0}(C) \subseteq Q_{s_{1}}(C) \subseteq Q_{s_{2}}(C) \subseteq Q_{1}(C)=Q(C)$

for $0 \leq s_{1} \leq s_{2} \leq 1$.

We recall the well-known Hölder's integral inequality which can be stated as follows, see [19].

Theorem 1 Let $p>1$ and $\frac{1}{p}+\frac{1}{q}=1$. If $f$ and $g$ are real functions defined on $[a, b]$ and if $|f|^{p}$ and $|g|^{q}$ are integrable functions on $[a, b]$, then

$\int_{a}^{b}|f(x) g(x)| \mathrm{d} x \leq\left(\int_{a}^{b}|f(x)|^{p} \mathrm{~d} x\right)^{\frac{1}{p}}\left(\int_{a}^{b}|g(x)|^{q} \mathrm{~d} x\right)^{\frac{1}{q}}$

with equality holding if and only if $A|f(x)|^{p}=B|g(x)|^{q}$ almost everywhere, where $A$ and $B$ are constants.

Theorem 2 (Power Mean Inequality, see [20]) Let $x=$ $\left(x_{i}\right), p=\left(p_{i}\right)$ be two positive $n$-tubles and let $r \in \mathbb{R} \cup$ $\{+\infty,-\infty\}, i=1,2, \ldots, n$. Then, taking $p_{n}=\sum_{k=1}^{n} p_{k}$, the $r$ th power mean of $x$ with weights $p$ is defined by

$M_{n}^{[r]}=\left\{\begin{array}{cc}\left(\frac{1}{p_{n}} \sum_{k=1}^{n} p_{k} x_{k}^{r}\right)^{\frac{1}{r}}, & r \neq+\infty, 0,-\infty \\ \left(\prod_{k=1}^{n} x_{k}^{p_{k}}\right)^{\frac{1}{p_{n}}}, & r=0 \\ \min \left(x_{1}, x_{2}, \ldots, x_{n}\right), & r=-\infty \\ \max \left(x_{1}, x_{2}, \ldots, x_{n}\right), & r=+\infty\end{array}\right.$

Note that if $-\infty \leq r<s \leq \infty$, then

$M_{n}^{[r]} \leq M_{n}^{[s]}$

(see, e.g., [21]).

Theorem 3 [1] Let $f \in Q(I), a, b \in I$ with $a<b$ and $f \in$ $L_{1}[a, b]$. Then one has the inequality

$f\left(\frac{a+b}{2}\right) \leq \frac{4}{b-a} \int_{a}^{b} f(x) \mathrm{d} x$.

Theorem 4 [1] Let $f \in P(I), a, b \in I$ with $a<b$ and $f \in$ $L_{1}[a, b]$. Then one has the inequality

$f\left(\frac{a+b}{2}\right) \leq \frac{2}{b-a} \int_{a}^{b} f(x) \mathrm{d} x \leq 2(f(a)+f(b))$.

Both inequalities are best possible.

We need the following inequalities:
Theorem 5 (see [21]) Let $f, g:[a, b] \rightarrow \mathbb{R}$ be integrable functions, both increasing or both decreasing. Furthermore, let $p:[a, b] \rightarrow \mathbb{R}_{+}$be an integrable function. Then

$\int_{a}^{b} p(x) f(x) \mathrm{d} x \int_{a}^{b} p(x) g(x) \mathrm{d} x \leq \int_{a}^{b} p(x) \mathrm{d} x \int_{a}^{b} p(x) f(x) g(x) \mathrm{d} x$.

If one of the functions $f$ or $g$ is nonincreasing and the other nondecreasing then the inequality in (5) is reversed. Inequality (5) is known in the literature as Čebyšev's inequality and so are the following special cases of (5):

$\frac{1}{b-a} \int_{a}^{b} f(x) \mathrm{d} x \int_{a}^{b} g(x) \mathrm{d} x \leq \int_{a}^{b} f(x) g(x) \mathrm{d} x$

and

$\int_{0}^{1} f(x) \mathrm{d} x \int_{0}^{1} g(x) \mathrm{d} x \leq \int_{0}^{1} f(x) g(x) \mathrm{d} x$.

Now, we are giving some necessary definitions and mathematical preliminaries of fractional calculus theory which are used throughout this paper, see [22].

Definition 4 Let $f \in L_{1}[a, b]$. The Riemann-Liouville integrals $J_{a^{+}}^{\alpha} f$ and $J_{b^{-}}^{\alpha} f$ of order $\alpha>0$ with $a \geq 0$ are defined by

$$
J_{a^{+}}^{\alpha} f(x)=\frac{1}{\Gamma(\alpha)} \int_{a}^{x}(x-t)^{\alpha-1} f(t) \mathrm{d} t, \quad x>a
$$

and

$J_{b^{-}}^{\alpha} f(x)=\frac{1}{\Gamma(\alpha)} \int_{x}^{b}(t-x)^{\alpha-1} f(t) \mathrm{d} t, \quad x<b$

respectively, where $\Gamma(\alpha)=\int_{0}^{\infty} e^{-u} u^{\alpha-1} \mathrm{~d} u$. Here is $J_{a^{+}}^{0} f(x)=J_{b^{-}}^{0} f(x)=f(x)$.

In the case of $\alpha=1$, the fractional integral reduces to the classical integral.

For some recent results connected with fractional integral inequalities see [22-29].

In [30, Özdemir et al. proved the following result for fractional integrals.

Lemma 1 Let $f: I \subset \mathbb{R} \rightarrow \mathbb{R}$ be a differentiable mapping on I with $a<r, a, r \in I$. If $f^{\prime} \in L[a, r]$, then the following equality for fractional integrals holds:

$$
\begin{aligned}
& \frac{f(a)+f(r)}{2}-\frac{\Gamma(\alpha+1)}{2(r-a)^{\alpha}}\left[J_{r^{-}}^{\alpha} f(a)+J_{a^{+}}^{\alpha} f(r)\right] \\
& =\frac{r-a}{2} \int_{0}^{1}\left[(1-t)^{\alpha}-t^{\alpha}\right] f^{\prime}(r+(a-r) t) \mathrm{d} t .
\end{aligned}
$$


The main purpose of this study is to obtain the inequalities for class of $s$-Godunova-Levin type functions.

\section{Main results}

In [31], S. S. Dragomir has written the following inequalities (6) and (8) without proof.

Theorem 6 Let $f \in Q_{s}(C)$, with $a<b$ and $f \in L_{1}[a, b]$, $C=[a, b], s \in[0,1]$. Then one has the inequalities

$f\left(\frac{a+b}{2}\right) \leq \frac{2^{s+1}}{b-a} \int_{a}^{b} f(x) \mathrm{d} x$

$\frac{\Gamma\left((1+s)^{2}\right)}{\Gamma(2+2 s)(b-a)} \int_{a}^{b} f(x) \mathrm{d} x \leq \frac{f(a)+f(b)}{s+1}$

and

$\frac{1}{b-a} \int_{a}^{b} f(x) \mathrm{d} x \leq \frac{f(a)+f(b)}{1-s}, \quad s \in[0,1)$

Proof $f \in Q_{s}(C)$, we have for all $x, y \in C=[a, b]$ with $t=\frac{1}{2}$

$2^{s}(f(x)+f(y)) \geq f\left(\frac{x+y}{2}\right)$

Now, if we choose $x=t a+(1-t) b, y=(1-t) a+t b$, we have

$2^{s}(f(t a+(1-t) b)+f((1-t) a+t b)) \geq f\left(\frac{a+b}{2}\right)$.

By integrating, we have that

$$
\begin{aligned}
2^{s} & {\left[\int_{0}^{1} f(t a+(1-t) b) \mathrm{d} t+\int_{0}^{1} f((1-t) a+t b) \mathrm{d} t\right] } \\
& \geq f\left(\frac{a+b}{2}\right)
\end{aligned}
$$

On the other hand,

$$
\begin{aligned}
\int_{0}^{1} f(t a+(1-t) b) \mathrm{d} t & =\int_{0}^{1} f((1-t) a+t b) \mathrm{d} t \\
& =\frac{1}{b-a} \int_{0}^{1} f(x) \mathrm{d} x
\end{aligned}
$$

we get the inequality (6) from (9).

For the proof of (7), if $f \in Q_{s}(C)$ for all $a, b \in C$ and $t \in(0,1)$, it yields

$t^{s}(1-t)^{s} f(t a+(1-t) b) \leq(1-t)^{s} f(a)+t^{s} f(b)$

and

$t^{s}(1-t)^{s} f((1-t) a+t b) \leq t^{s} f(a)+(1-t)^{s} f(b)$.

By adding these inequalities and integrating over $[0,1]$, we find that

$$
\begin{aligned}
& \int_{0}^{1} t^{s}(1-t)^{s}[f(t a+(1-t) b)+f((1-t) a+t b)] \mathrm{d} t \\
& \quad \leq \frac{2}{s+1}[f(a)+f(b)] .
\end{aligned}
$$

Now, by a simple computation, we have

$\int_{0}^{1} t^{s}(1-t)^{s} f(t a+(1-t) b) \mathrm{d}$ and $\int_{0}^{1} t^{s}(1-t)^{s} f((1-t) a+t b) \mathrm{d} t$.

Let be $g(t)=t^{s}(1-t)^{s}$. We take symmetric of the functions $g(t)$ and $f$, respectively, $\frac{1}{2}$ and $\frac{a+b}{2}$. Also, let the functions $f$ and $g$ both be either increasing or decreasing. By applying Čebyš ev's inequality, we have

$$
\begin{aligned}
\int_{0}^{1} t^{s}(1-t)^{s} f(t a+(1-t) b) \mathrm{d} t & =\int_{0}^{1} t^{s}(1-t)^{s} f((1-t) a+t b) \mathrm{d} t \\
& \geq \int_{0}^{1} t^{s}(1-t)^{s} \mathrm{~d} t \int_{0}^{1} f((1-t) a+t b) \mathrm{d} t \\
& =\frac{\Gamma\left((1+s)^{2}\right)}{\Gamma(2+2 s)(b-a)} \int_{a}^{b} f(x) \mathrm{d} x .
\end{aligned}
$$

To obtain the inequality (8), as $f \in Q_{s}(C)$, we have

$f(t a+(1-t) b) \leq t^{-s} f(a)+(1-t)^{-s} f(b)$

integrating this inequality on $[0,1]$, we get

$$
\begin{aligned}
\int_{0}^{1} f(t a+(1-t) b) \mathrm{d} t & \leq f(a) \int_{0}^{1} t^{-s} \mathrm{~d} t+f(b) \int_{0}^{1}(1-t)^{-s} \mathrm{~d} t \\
& =\frac{f(a)+f(b)}{1-s}, \quad(s \in[0,1))
\end{aligned}
$$

As the change of variable $x=t a+(1-t) b$ gives us

$$
\int_{0}^{1} f(t a+(1-t) b) \mathrm{d} t=\frac{1}{b-a} \int_{a}^{b} f(x) \mathrm{d} x
$$

which completes the proof of the inequality (8).

Theorem 7 Combining the inequalities (2.1) and (2.3) under the conditions of Theorem 6, we get

$f\left(\frac{a+b}{2}\right) \leq \frac{2^{s+1}}{b-a} \int_{a}^{b} f(x) \mathrm{d} x \leq 2^{s+1} \frac{f(a)+f(b)}{1-s}$.

Remark 1 If we choose $s=1$ in (6) and (7), we obtain the inequality (3) and right hand side of (4), respectively.

Theorem 8 Let $f: I \subseteq \mathbb{R} \rightarrow[0, \infty)$ be a differentiable mapping on I, $a, r \in I$ and $a<r$. If $\left|f^{\prime}\right| \in Q_{\alpha}(I)$ with $\alpha \in$ $[0,1), t \in(0,1)$, then the following inequality for fractional integrals holds:

$$
\begin{aligned}
& \left|\frac{f(a)+f(r)}{2}-\frac{\Gamma(\alpha+1)}{2(r-a)^{\alpha}}\left[J_{r^{-}}^{\alpha} f(a)+J_{a^{+}}^{\alpha} f(r)\right]\right| \\
& \leq \frac{(r-a)}{2}\left\{\pi \alpha \operatorname{cosec}(\pi \alpha)\left[\left|f^{\prime}(r)\right|+\left|f^{\prime}(a)\right|\right]+2 \beta_{\frac{1}{2}}(1-\alpha, 1+\alpha)\right\}
\end{aligned}
$$


where $\beta_{x}(y, z)=\int_{0}^{x} t^{y-1}(1-t)^{z-1} \mathrm{~d} t, 0 \leq x \leq 1$ is incomplete Beta function.

Proof Using the Lemma 1 and $\left|f^{\prime}\right| \in Q_{\alpha}(I)$, it follows that $\left|\frac{f(a)+f(r)}{2}-\frac{\Gamma(\alpha+1)}{2(r-a)^{\alpha}}\left[J_{r^{-}}^{\alpha} f(a)+J_{a^{+}}^{\alpha} f(r)\right]\right|$
$\leq \frac{(r-a)}{2} \int_{0}^{1}\left|(1-t)^{\alpha}-t^{\alpha}\right|\left|f^{\prime}(r+(a-r) t)\right| \mathrm{d} t$.

Since

$\left|f^{\prime}(r+(a-r) t)\right|=\left|f^{\prime}(t a+(1-t) r)\right| \leq \frac{1}{t^{\alpha}}\left|f^{\prime}(a)\right|+\frac{1}{(1-t)^{\alpha}}\left|f^{\prime}(r)\right|$

$\left|\frac{f(a)+f(r)}{2}-\frac{\Gamma(\alpha+1)}{2(r-a)^{\alpha}}\left[J_{r^{-}}^{\alpha} f(a)+J_{a^{+}}^{\alpha} f(r)\right]\right|$

$\leq \frac{(r-a)}{2} \int_{0}^{1}\left|(1-t)^{\alpha}-t^{\alpha}\right|\left[\frac{1}{t^{\alpha}}\left|f^{\prime}(a)\right|+\frac{1}{(1-t)^{\alpha}}\left|f^{\prime}(r)\right|\right] \mathrm{d} t$

$=\frac{(r-a)}{2}\left\{\int_{0}^{\frac{1}{2}}\left[(1-t)^{\alpha}-t^{\alpha}\right]\left[\frac{1}{t^{\alpha}}\left|f^{\prime}(a)\right|+\frac{1}{(1-t)^{\alpha}}\left|f^{\prime}(r)\right|\right] \mathrm{d} t\right.$

$\left.+\int_{\frac{1}{2}}^{1}\left[t^{\alpha}-(1-t)^{\alpha}\right]\left[\frac{1}{t^{\alpha}}\left|f^{\prime}(a)\right|+\frac{1}{(1-t)^{\alpha}}\left|f^{\prime}(r)\right|\right] \mathrm{d} t\right\}$

On the other hand, by a simple computation, we have

$\int_{0}^{\frac{1}{2}}\left[\frac{(1-t)^{\alpha}-t^{\alpha}}{t^{\alpha}}\right] \mathrm{d} t=\beta_{\frac{1}{2}}(1-\alpha, 1+\alpha)-\frac{1}{2}$

$\int_{0}^{\frac{1}{2}}\left[\frac{(1-t)^{\alpha}-t^{\alpha}}{(1-t)^{\alpha}}\right] \mathrm{d} t=\frac{1}{2}-\beta_{\frac{1}{2}}(\alpha+1,1-\alpha)$

$\int_{\frac{1}{2}}^{1}\left[\frac{t^{\alpha}-(1-t)^{\alpha}}{t^{\alpha}}\right] \mathrm{d} t=\frac{1}{2}-\pi \alpha \cos e c(\pi \alpha)+\beta_{\frac{1}{2}}(\alpha+1,1-\alpha)$

and

$\int_{\frac{1}{2}}^{1}\left[\frac{t^{\alpha}-(1-t)^{\alpha}}{(1-t)^{\alpha}}\right] \mathrm{d} t=\pi \alpha \operatorname{cosec}(\pi \alpha)-\beta_{\frac{1}{2}}(1+\alpha, 1-\alpha)-\frac{1}{2}$.

Since, finally

$\left|f^{\prime}(r)\right|-\left|f^{\prime}(a)\right| \leq\left|f^{\prime}(r)\right|+\left|f^{\prime}(a)\right|$.

Hence, we obtain the inequality (10).

Theorem 9 Let $f: I \subset \mathbb{R} \rightarrow[0, \infty)$ be a differentiable mapping of $I, a, r \in I$ and $a<r$. If $\left|f^{\prime}\right|^{q} \in Q_{s}(I)$ with $\alpha \in[0,1], t \in(0,1)$, then the following inequality for fractional integrals holds:

$$
\begin{aligned}
& \left|\frac{f(a)+f(r)}{2}-\frac{\Gamma(\alpha+1)}{2(r-a)^{\alpha}}\left[J_{r^{\alpha}}^{\alpha} f(a)+J_{a^{+}}^{\alpha} f(r)\right]\right| \\
& \leq \frac{(r-a)}{2(\alpha p+1)^{\frac{1}{p}}(1-s)^{\frac{1}{q}}}\left(\left|f^{\prime}(a)\right|^{q}+\left|f^{\prime}(r)\right|^{q}\right)^{\frac{1}{q}}
\end{aligned}
$$

where $\frac{1}{p}+\frac{1}{q}=1, s \in[0,1), \Gamma($.$) is Gamma function.$

Proof From Lemma 1 and using Hölder inequality with properties of modulus, we have

$$
\begin{aligned}
& \left|\frac{f(a)+f(r)}{2}-\frac{\Gamma(\alpha+1)}{2(r-a)^{\alpha}}\left[J_{r^{\alpha}}^{\alpha} f(a)+J_{a^{\alpha}}^{\alpha} f(r)\right]\right| \\
& \leq \frac{(r-a)}{2} \int_{0}^{1}\left|(1-t)^{\alpha}-t^{\alpha}\right|\left|f^{\prime}(r+(a-r) t)\right| \mathrm{d} t \\
& \leq \frac{(r-a)}{2}\left(\int_{0}^{1}\left|(1-t)^{\alpha}-t^{\alpha}\right|^{p} \mathrm{~d} t\right)^{\frac{1}{p}}\left(\int_{0}^{1}\left|f^{\prime}(r+(a-r) t)\right|^{q} \mathrm{~d} t\right)^{\frac{1}{q}} .
\end{aligned}
$$

We know that for $\alpha \in(0,1]$ and $\forall t_{1}, t_{2} \in(0,1)$,

$$
\left|t_{1}^{\alpha}-t_{2}^{\alpha}\right| \leq\left|t_{1}-t_{2}\right|^{\alpha}
$$

therefore,

$$
\begin{aligned}
\int_{0}^{1}\left|(1-t)^{\alpha}-t^{\alpha}\right|^{p} \mathrm{~d} t & \leq \int_{0}^{1}|1-2 t|^{\alpha p} \mathrm{~d} t \\
& =\int_{0}^{\frac{1}{2}}(1-2 t)^{\alpha p} \mathrm{~d} t+\int_{\frac{1}{2}}^{1}(2 t-1)^{\alpha p} \mathrm{~d} t \\
& =\frac{1}{\alpha p+1} .
\end{aligned}
$$

Since $\left|f^{\prime}\right| \in Q_{s}(I)$, we obtain

$\left|f^{\prime}(r+(a-r) t)\right|=\left|f^{\prime}(t a+(1-t) r)\right| \leq \frac{1}{t^{s}}\left|f^{\prime}(a)\right|+\frac{1}{(1-t)^{s}}\left|f^{\prime}(r)\right|$.

Hence, we get

$$
\begin{gathered}
\left|\frac{f(a)+f(r)}{2}-\frac{\Gamma(\alpha+1)}{2(r-a)^{\alpha}}\left[J_{r^{\alpha}}^{\alpha} f(a)+J_{a^{+}}^{\alpha} f(r)\right]\right| \\
\leq \frac{(r-a)}{2(\alpha p+1)^{\frac{1}{p}}(1-s)^{\frac{1}{q}}}\left(\left|f^{\prime}(a)\right|^{q}+\left|f^{\prime}(r)\right|^{q}\right)^{\frac{1}{q}}
\end{gathered}
$$

which completes the proof.

Corollary 1 In Theorem 9 , if we choose $\alpha=1$ and $s=0$, then we have

$$
\begin{aligned}
& \left|\frac{f(a)+f(r)}{2}-\frac{1}{(r-a)} \int_{a}^{r} f(t) \mathrm{d} t\right| \\
& \quad \leq \frac{(r-a)}{2(p+1)^{\frac{1}{p}}(1-s)^{\frac{1}{q}}}\left(\left|f^{\prime}(a)\right|^{q}+\left|f^{\prime}(r)\right|^{q}\right)^{\frac{1}{q}} \\
& \quad \leq \frac{(r-a)}{2}\left(\left|f^{\prime}(a)\right|+\left|f^{\prime}(r)\right|\right) .
\end{aligned}
$$

Proof Let $a_{1}=\left|f^{\prime}(a)\right|^{q}, \quad b_{1}=\left|f^{\prime}(r)\right|^{q}, \quad 0<\frac{1}{q}<1 \quad$ for $q>1$. Using the fact

$\sum_{i=1}^{n}\left(a_{i}+b_{i}\right)^{r} \leq \sum_{i=1}^{n} a_{i}^{r}+\sum_{i=1}^{n} b_{i}^{r}$ 
for $a_{1}, a_{2}, \ldots, a_{n} \geq 0, \quad b_{1}, b_{2}, \ldots, b_{n} \geq 0$, we obtain the inequality (11) and since $\frac{1}{2} \leq\left(\frac{1}{p+1}\right)^{\frac{1}{p}} \leq 1, p \in(0,1)$.

Theorem 10 Let $f: I \subset \mathbb{R} \rightarrow[0, \infty)$ be a differentiable mapping an I, a, $r \in I, a<r$ and $q \geq 1$. If $\left|f^{\prime}\right|^{q} \in Q_{\alpha}(I)$ with $\alpha \in[0,1), t \in(0,1)$, then the following inequality for fractional integrals hold:

$$
\begin{aligned}
& \left|\frac{f(a)+f(r)}{2}-\frac{\Gamma(\alpha+1)}{2(r-a)^{\alpha}}\left[J_{r^{-}}^{\alpha} f(a)+J_{a^{+}}^{\alpha} f(r)\right]\right| \\
& \leq \frac{(r-a)}{2^{\frac{1}{q}}(\alpha+1)^{1-\frac{1}{q}}}\left(1-\frac{1}{2^{\alpha}}\right)^{1-\frac{1}{q}}\left[\left(2 \beta_{\frac{1}{2}}(1-\alpha, 1+\alpha)-\pi \alpha \operatorname{cosec}(\pi \alpha)\right)\right]^{\frac{1}{q}} \\
& \times\left(\left|f^{\prime}(a)\right|+\left|f^{\prime}(r)\right|\right) .
\end{aligned}
$$

Proof From Lemma 1 and using the well-known power mean inequality, we have

$$
\begin{aligned}
& \left|\frac{f(a)+f(r)}{2}-\frac{\Gamma(\alpha+1)}{2(r-a)^{\alpha}}\left[J_{r^{-}}^{\alpha} f(a)+J_{a^{+}}^{\alpha} f(r)\right]\right| \\
& \leq \frac{(r-a)}{2} \int_{0}^{1}\left|(1-t)^{\alpha}-t^{\alpha}\right|\left|f^{\prime}(r+(a-r) t)\right| \mathrm{d} t \\
& \leq \frac{(r-a)}{2}\left(\int_{0}^{1}\left|(1-t)^{\alpha}-t^{\alpha}\right| \mathrm{d} t\right)^{1-\frac{1}{q}} \\
& \quad \times\left(\int_{0}^{1}\left|(1-t)^{\alpha}-t^{\alpha}\right|\left|f^{\prime}(r+(a-r) t)\right|^{q} \mathrm{~d} t\right)^{\frac{1}{q}} .
\end{aligned}
$$

On the other hand, we have

$$
\begin{aligned}
\int_{0}^{1}\left|(1-t)^{\alpha}-t^{\alpha}\right| \mathrm{d} t & =\int_{0}^{\frac{1}{2}}\left[(1-t)^{\alpha}-t^{\alpha}\right] \mathrm{d} t+\int_{\frac{1}{2}}^{1}\left[t^{\alpha}-(1-t)^{\alpha}\right] \mathrm{d} t \\
& =\frac{2}{\alpha+1}\left(1-\frac{1}{2^{\alpha}}\right) .
\end{aligned}
$$

Since $\left|f^{\prime}\right| \in Q_{\alpha}(I)$, we have

$$
\begin{aligned}
\left|f^{\prime}(r+(a-r) t)\right|^{q}= & \left|f^{\prime}(t a+(1-t) r)\right|^{q} \leq \frac{1}{t^{\alpha}}\left|f^{\prime}(a)\right|^{q} \\
& +\frac{1}{(1-t)^{\alpha}}\left|f^{\prime}(r)\right|^{q}
\end{aligned}
$$

and

$$
\begin{aligned}
& \int_{0}^{1}\left|(1-t)^{\alpha}-t^{\alpha}\right|\left|f^{\prime}(r+(a-r) t)\right|^{q} \mathrm{~d} t \\
& \leq \int_{0}^{1}\left|(1-t)^{\alpha}-t^{\alpha}\right|\left[\frac{1}{t^{\alpha}}\left|f^{\prime}(a)\right|^{q}+\frac{1}{(1-t)^{\alpha}}\left|f^{\prime}(r)\right|^{q}\right] \mathrm{d} t \\
& \leq \int_{0}^{\frac{1}{2}}\left[(1-t)^{\alpha}-t^{\alpha}\right]\left[\frac{1}{t^{\alpha}}\left|f^{\prime}(a)\right|^{q}+\frac{1}{(1-t)^{\alpha}}\left|f^{\prime}(r)\right|^{q}\right] \mathrm{d} t \\
& \quad+\int_{\frac{1}{2}}^{1}\left[t^{\alpha}-(1-t)^{\alpha}\right]\left[\frac{1}{t^{\alpha}}\left|f^{\prime}(a)\right|^{q}+\frac{1}{(1-t)^{\alpha}}\left|f^{\prime}(r)\right|^{q}\right] \mathrm{d} t .
\end{aligned}
$$

and since $\sum_{i=1}^{n}\left(a_{i}+b_{i}\right)^{r} \leq \sum_{i=1}^{n} a_{i}{ }^{r}+\sum_{i=1}^{n} b_{i}{ }^{r}$, we obtain the required inequality (12).

\section{Applications to numerical integration}

We may not be given a formula for $f(x)$ as a function of $x$. For instance, $f(x)$ may be an unknown function whose values are at certain points of the interval $[a, b]$. In this case, we investigate the problem of approximating the value of the integral $I=\int_{a}^{b} f(x) \mathrm{d} x$ using only the values of $f(x)$ at finitely many points of $[a, b]$. Obtaining such an approximation is called numerical integration. That is why, there are three methods for evaluating definite integrals numerically. One of them is Trapezoid Rule.

Let $d$ be a division of the interval $[a, r]$, i.e., $d: a=$ $x_{0}<x_{1}<\cdots<x_{n-1}<x_{n}=r$, and consider the trapezoidal formula

$$
T_{n}(f, d)=\sum_{i=0}^{n-1} \frac{f\left(x_{i}\right)+f\left(x_{i+1}\right)}{2}\left(x_{i+1}-x_{i}\right) .
$$

So, the following approximation of the integral $\int_{a}^{b} f(x) \mathrm{d} x$ holds:

$$
\int_{a}^{b} f(x) \mathrm{d} x \approx T_{n}(f, d)+E_{n}(f, d)
$$

where the approximation error $E_{n}(f, d)$ of the integral $\int_{a}^{b} f(x) \mathrm{d} x$ by the trapezoidal formula $T_{n}(f, d)$ satisfies

$$
\left|E_{n}(f, d)\right| \leq \frac{M}{12} \sum_{i=0}^{n-1}\left(x_{i+1}-x_{i}\right)^{3} .
$$

We shall propose some new estimates of the remainder term $E_{n}(f, d)$.

Proposition 1 Let $f$ be a differentiable mapping on $I^{\circ}$, $a, r \in I^{\circ}$ with $a<r$. If $\left|f^{\prime}\right|$ is $p$-convex on $[a, r]$, then for every division $d$ of $[a, r]$, the following holds:

$$
\begin{aligned}
\left|E_{n}(f, d)\right| & \leq \frac{1}{2} \sum_{i=0}^{n-1}\left(x_{i+1}-x_{i}\right)^{2}\left(\left|f^{\prime}\left(x_{i}\right)\right|+\left|f^{\prime}\left(x_{i+1}\right)\right|\right) \\
& \leq \sum_{i=0}^{n-1}\left(x_{i+1}-x_{i}\right)^{2} \max \left\{\left|f^{\prime}(a)\right|,\left|f^{\prime}(r)\right|\right\} .
\end{aligned}
$$

Proof Applying Corollary 1 on the subinterval $\left[x_{i}, x_{i+1}\right]$ $(i=0,1,2, \ldots, n-1)$ of the division $d$, we get

$$
\begin{gathered}
\left|\frac{f\left(x_{i}\right)+f\left(x_{i+1}\right)}{2}\left(x_{i+1}-x_{i}\right)-\int_{x_{i}}^{x_{i+1}} f(x) \mathrm{d} x\right| \\
\leq \frac{\left(x_{i+1}-x_{i}\right)^{2}\left(\left|f^{\prime}\left(x_{i}\right)\right|+\left|f^{\prime}\left(x_{i+1}\right)\right|\right)}{2} .
\end{gathered}
$$

Summing over $i$ from 0 to $n-1$ on taking into account that $\left|f^{\prime}\right|$ is $p$-convex, we deduce, by the triangle inequality that 


$$
\begin{aligned}
\left|T_{n}(f, d)-\int_{a}^{b} f(x) \mathrm{d} x\right| & \leq \frac{1}{2} \sum_{i=0}^{n-1}\left(x_{i+1}-x_{i}\right)^{2}\left(\left|f^{\prime}\left(x_{i}\right)\right|+\left|f^{\prime}\left(x_{i+1}\right)\right|\right) \\
& \leq \max \left\{\left|f^{\prime}\left(x_{i}\right)\right|,\left|f^{\prime}\left(x_{i+1}\right)\right|\right\} \sum_{i=0}^{n-1}\left(x_{i+1}-x_{i}\right)^{2} \\
& \leq \max \left\{\left|f^{\prime}(a)\right|,\left|f^{\prime}(r)\right|\right\} \sum_{i=0}^{n-1}\left(x_{i+1}-x_{i}\right)^{2} .
\end{aligned}
$$

10. Mitrinović, D.S., Pečarić, J.E.: Note on a class of functions of Godunova and Levin. C. R. Math. Rep. Acad. Sci. Canada 12(1), 33-36 (1990)

11. Pečarić, J.E., Dragomir, S.S.: A generalization of Hadamard's inequality for isotonic linear functionals. Radovi Mat. (Sarajevo) 7, 103-107 (1991)

12. Radulescu, M., Radulescu, S., Alexandrescu, P.: On the Godunova-Levin-Schur class of functions. Math. Inequal. Appl. 12(4), 853-862 (2009)

13. Sarıkaya, M.Z., Set, E., Özdemir, M.E.: On new inequalities of Simpson's type for s-convex functions. Comput. Math. Appl. 60, 2191-2199 (2010)

Proposition 2 Let $f$ be a differentiable mapping on $I^{\circ} \subset I, a, r \in I^{\circ}$ with $a<r$ and let $\frac{1}{p}+\frac{1}{q}=1$. If $\left|f^{\prime}\right|^{q} \in$ $Q_{s}\left(I^{\circ}\right)$ with $\alpha=1, t \in(0,1)$. Then for every division of $[a, r]$, the following holds:

$$
\begin{aligned}
\left|E_{n}(f, d)\right| & \leq \frac{1}{2(p+1)^{\frac{1}{q}}(1-s)^{\frac{1}{q}}} \sum_{i=o}^{n-1}\left(x_{i+1}-x_{i}\right)^{2}\left[\left|f^{\prime}\left(x_{i}\right)\right|^{q}+\left|f^{\prime}\left(x_{i+1}\right)\right|^{q}\right]^{\frac{1}{q}} \\
& \leq \frac{\max \left\{\left|f^{\prime}(a)\right|,\left|f^{\prime}(r)\right|\right\}}{2(p+1)^{\frac{1}{q}}(1-s)^{\frac{1}{q}}} \sum_{i=o}^{n-1}\left(x_{i+1}-x_{i}\right)^{2} .
\end{aligned}
$$

Proof If we apply the Theorem 9 for $\alpha=1$, the proof is similar to that of Proposition 1.

Open Access This article is distributed under the terms of the Creative Commons Attribution License which permits any use, distribution, and reproduction in any medium, provided the original author(s) and the source are credited.

\section{References}

1. Dragomir, S.S., Pearce, C.E.M.: Selected Topics on HermiteHadamard Inequalities and Applications. RGMIA Monographs. Victoria University, Melbourne (2000)

2. Pečarić, J.E., Proschan, F., Tong, Y.L.: Convex Functions. Partial Orderings and Statistical Applications. Academic Press, Boston (1992)

3. Kırmacı, U.S., Bakula, M.K., Özdemir M.E., Pe čarić, J.: Hadamard-type inequalities for s-convex functions. Appl. Math. and Comp. 193, 26-35 (2007)

4. Özdemir, M.E., Kırmacı, U.S.: Two new theorem on mappings uniformly continuous and convex with applications to quadrature rules and means. Appl. Math. and Comp. 143, 269-274 (2003)

5. Sarıkaya, M.Z., Set, E., Özdemir, M.E.: On some new inequalities of Hadamard type involving $h$-convex functions. Acta Math. Univ. Comenianae, vol. LXXIX, 2, pp. 265-272 (2010)

6. Godunova, E.K., Levin, V.I.: Inequalities for functions of a broad class that contains convex, monotone and some other forms of functions. In: Proceedings of (Russian) Numerical Mathematics and Mathematical Physics (Russian), vol. 166, pp. 138-142. Moskov. Gos. Ped. Inst., Moscow (1985)

7. Dragomir, S.S., Mond, B.: On Hadamard's inequality for a class of functions of Godunova and Levin. Indian J. Math. 39(1), 1-9 (1997)

8. Dragomir, S.S., Pearce, C.E.M.: On Jensen's inequality for a class of functions of Godunova and Levin. Period. Math. Hungar. 33(2), 93-100 (1996)

9. Dragomir, S.S., Pečarić, J.E., Persson, L.: Some inequalities of Hadamard type. Soochow J. Math. 21(3), 335-341 (1995)
14. Avc1, M., Kavurmac1, H., Özdemir, M.E.: New inequalities of Hermite-Hadamard type via s-convex functions in the second sense with applications. Appl. Math. Comput. 217, 5171-5176 (2011)

15. Kirmaci, U.S., Bakula, M.K., Özdemir, M.E., Pečari ć, J.E.: Hadamard-type inequalities for s-convex functions. Appl. Math. Comput. 193(1), 26-35 (2007)

16. Set, E., Özdemir, M.E., Sarıkaya, M.Z.: New inequalities of Ostrowski's type for s-convex functions in the second sense with applications. Facta Univ. Ser. Math. Inform. 27(1), 67-82 (2012)

17. Dragomir, S.S., Fitzpatrick, S.: The Hadamard inequalities for s-convex functions in the second sense. Demonstr. Math. 32(4), 687-696 (1999)

18. Dragomir, S.S.: Integral inequalities of Jensen type for $\lambda$-convex functions. In: Proceedings of RGMIA, Res. Rep. Coll. 17 (2014)

19. Mitrinović, D.S.: Analytic Inequalities. Springer, New York (1970)

20. Bullen, P.S., Mitrinović, D.S., Vasić, P.M.: Means and their inequalities. In: Proceedings of Mathematical and its Applications, D. Reidel, Dortdrecht (1988)

21. Mitrinović, D.S., Pečarić, J.E., Fink, A.M.: Mathematics and its Applications. Classical and new inequalities in analysis. Kluwer Academic Publishers, Dordrecht (1993)

22. Samko, S.G., Kilbas, A.A., Marichev, O.I.: Fractional Integrals and Derivatives Theory and Application. Gordan and Breach Science, New York (1993)

23. Belarbi, S., Dahmani, Z.: On some new fractional integral inequalities, J. Ineq. Pure Appl. Math. 10(3), Art. 86 (2009)

24. Dahmani, Z.: New inequalities in fractional integrals. Int. J. Nonlinear Sci. 9(4), 493-497 (2010)

25. Dahmani, Z.: On Minkowski and Hermite-Hadamard integral inequalities via fractional integration. Ann. Funct. Anal. 1(1), 51-58 (2010)

26. Dahmani, Z., Tabharit, L., Taf, S.: Some fractional integral inequalities. Nonl. Sci. Lett. A. 1(2), 155-160 (2010)

27. Dahmani, Z., Tabharit, L., Taf, S.: New generalizations of Gruss inequality using Riemann-Liouville fractional integrals. Bull. Math. Anal. Appl. 2(3), 93-99 (2010)

28. Özdemir, M.E., Kavurmac1, H., Avc1, M.: New inequalities of Ostrowski type for mappings whose derivatives are $(\alpha, m)$-convex via fractional integrals. In: Proceedings of RGMIA Research Report Collection, 15, Article 10, pp. 8 (2012)

29. Özdemir, M.E., Sarıkaya, M.Z., Yıldız, Ç.: New Generalizations of Ostrowski-Like Type Inequalities for Fractional Integrals, Submitted (2015)

30. Özdemir, M.E., Dragomir, S.S., Yıldız, Ç.: The Hadamard inequality for convex function via fractional integrals. Acta Math. Sci. 33B(5), 1293-1299 (2013)

31. Dragomir, S.S.: Inequalities of Hermite-Hadamard type for $\lambda$ convex functions on linear spaces, preprint RGMIA Res. Rep. Coll. 17 (2014) 